\title{
Intra-individual variation in resting metabolic rate during the menstrual cycle
}

\author{
C. Jeya K. Henry ${ }^{1}$, Helen J. Lightowler ${ }^{1}$ and Jonathan Marchini ${ }^{2}$ \\ ${ }^{1}$ Nutrition and Food Science Group, School of Biological and Molecular Sciences, \\ Oxford Brookes University, Gipsy Lane Campus, Headington, Oxford OX3 OBP, UK \\ ${ }^{2}$ Department of Statistics, University of Oxford, 1 South Parks Road, Oxford OX1 3TG, UK
}

(Received 9 January 2002 - Revised 10 December 2002 - Accepted 6 January 2003)

\begin{abstract}
Little information exists on the extent of day-to-day intra-individual variation in resting metabolic rate (RMR) in women. The present study has investigated the intra-individual variation in RMR of women during the menstrual cycle. Nineteen women (naturally cycling non-pill users) were recruited to the study. Anthropometric and RMR measurements were taken at least three times per week for the duration of one complete menstrual cycle; measurements were taken for a second, consecutive cycle in eight of the nineteen subjects. RMR was measured by indirect calorimetry using a ventilated hood system under standardized conditions. The measurements made throughout each complete menstrual cycle were averaged and the levels of inter- and intra-individual variation in RMR were assessed by determining the CV (\%). Mean RMR of the group was 5686 (SD 674) $\mathrm{kJ} / \mathrm{d}$; inter-individual variation in RMR was $11.8 \%$. There were wide differences in the intra-individual variation in RMR of women (CV range $1 \cdot 7-10 \cdot 4 \%)$. The $\mathrm{CV}$ in ten subjects was small $(2-4 \%)$, while the $\mathrm{CV}$ in nine women was high $(5-10 \%)$, indicating a significant variation in RMR during the menstrual cycle in certain subjects. Using statistical models, it has been shown that there was a significant effect on RMR due to a subject-specific level of variability; this was the case even when accounting for a possible training effect. In conclusion, the findings from our present study show that RMR cannot be assumed to be 'stable' in all women. The implications of intraindividual variation in RMR and its impact on energy balance needs further research.
\end{abstract}

Resting metabolic rate: Intra-individual variation: Menstrual cycle

Throughout most of human history, weight gain and fat storage have been viewed as signs of health and prosperity (Bray, 1997). Today, obesity poses an increasing threat to the health of the nation. In the UK alone, $>50 \%$ of the adult population are classified as overweight or obese (Erens \& Primatesta, 1999). Obesity is defined as an excess accumulation of body fat. This condition can only arise if energy intake is greater than requirements, energy expenditure lower, or due to a combination of these two factors. Modest fluctuations in daily energy intake and expenditure could lead to a large imbalance in energy over time, leading to obesity.

Women have a greater degree of adiposity than men. This sexual dimorphism appears to be universal (James \& Ralph, 1999). However, there is currently no widely accepted explanation for women's susceptibility to gain more body fat than men.
The Food and Agriculture Organization/World Health Organization/United Nations University (1985) report on energy and protein requirements recommended the use of energy expenditure rather than energy intake as the basis for determining energy requirements in human subjects. The largest component of total energy expenditure is RMR.

Previous research has indicated that the RMR of an individual is markedly stable over time (Shetty \& Soares, 1988; Henry et al. 1989). Indeed, the biological 'stability' of RMR underpinned its use to estimate energy requirements. However, these observations have been largely made in men, and little information exists on the intra-individual variation in RMR in women.

Previous studies investigating RMR in women have had conflicting results. Some studies suggest that RMR changes with the menstrual cycle (Wakeham, 1923; Hitchcock \& Wardwell, 1929; Solomon et al. 1982; Meijer et al.

Abbreviation: RMR, resting metabolic rate.

* Corresponding author: Professor Jeya Henry, fax +44 1865 484017, email jhenry@brookes.ac.uk 
1992), whereas other studies have shown no demonstrable difference (Blunt \& Dye, 1921; Wiltshire, 1921; Howe et al. 1993; Weststrate, 1993; Piers et al. 1995). More recently, it has been suggested that the menstrual cycle might influence RMR in some individuals (Curtis et al. 1996a). Many of the previous studies were performed on a limited number of female subjects. In light of this, the aim of our present study was to investigate the intra-individual variation in RMR in a larger number ( $n$ 19) of women (naturally cycling non-pill users) during the menstrual cycle. In particular, the question of interest was to assess whether there was a subject-specific component of variance, i.e. whether the variation of RMR during the menstrual cycle for each subject was different.

\section{Methods \\ Subjects}

Nineteen women were recruited to the study. Subjects were staff and students (undergraduate and postgraduate) from Oxford Brookes University and were healthy, premenopausal women. None of the subjects were using oral contraceptive pills. Ethical approval for the study was obtained from the Ethics Committee at Oxford Brookes University and written informed consent was obtained from all subjects before participation in the study.

\section{Anthropometric measurements}

All anthropometric measurements were made in the fasting state. Height was recorded to the nearest centimetre using a stadiometer (Seca Ltd, Birmingham, UK), with subjects standing erect and without shoes. Body weight was recorded to the nearest $0.1 \mathrm{~kg}$ using professional dial scales (Healthometer, Bridgeview, IL, USA), with subjects wearing light clothing and no shoes. BMI was calculated using the standard formula: weight $(\mathrm{kg}) /$ height $(\mathrm{m})^{2}$.

Waist circumference was measured midway between the lowest rib margin and iliac crest (Gibson, 1991) and recorded to the nearest $0 \cdot 1 \mathrm{~cm}$. Total body fat was estimated from the sum of four skinfold thickness measurements taken at the triceps, biceps, subscapular and suprailiac sites (with Holtain Tanner Whitehouse skinfold callipers; Holtain Ltd, Crosswell, Wales, UK) using the Durnin \& Womersley (1974) equations. The physical characteristics of the subjects are summarized in Table 1.

Table 1. Physical characteristics of the nineteen subjects (Mean values, standard deviations and ranges)

\begin{tabular}{|c|c|c|c|}
\hline & Mean & SD & Range \\
\hline Age (years) & $23 \cdot 1$ & 5.0 & 19-35 \\
\hline Height $(\mathrm{m})$ & 1.65 & 0.06 & $1.55-1.75$ \\
\hline Body weight (kg) & $69 \cdot 1$ & $15 \cdot 7$ & $51 \cdot 5-104 \cdot 2$ \\
\hline $\mathrm{BMI}\left(\mathrm{kg} / \mathrm{m}^{2}\right)$ & $25 \cdot 4$ & $6 \cdot 1$ & $19 \cdot 1-40 \cdot 2$ \\
\hline WC $(\mathrm{cm})$ & $76 \cdot 5$ & $9 \cdot 8$ & $63 \cdot 9-94 \cdot 0$ \\
\hline Fat mass ( $\%$ body weight) & $29 \cdot 7$ & $5 \cdot 8$ & $20.7-39.3$ \\
\hline Lean body mass $(\mathrm{kg})$ & $47 \cdot 8$ & $7 \cdot 4$ & $38 \cdot 0-65 \cdot 1$ \\
\hline
\end{tabular}

WC, waist circumference.

\section{Resting metabolic rate measurement}

RMR was measured by indirect calorimetry using a ventilated hood system (Deltatrac, Datex-Ohmeda Intrumentarium Corp., Helsinki, Finland). The calorimeter was calibrated with a reference gas mixture $\left(\mathrm{O}_{2}-\mathrm{CO}_{2}, 95: 5\right.$, $\mathrm{v} / \mathrm{v})$ before each measurement session. Alcohol checks were performed every 3-6 months. All measurements were carried out in standardized conditions: early in the morning, with the subject at complete rest in a thermoneutral environment $\left(24-26^{\circ} \mathrm{C}\right)$ and at least $12 \mathrm{~h}$ after the last meal. Subjects were asked to lie completely still during the measurements. After $10 \mathrm{~min}$ to allow for stabilization and for subjects to acclimatize to the canopy and instrument noise, respiratory gas exchange data were collected for $20 \mathrm{~min}$ and the average RMR calculated.

Subjects notified the investigator (H. J. L.) at the start of the menses; this was defined as day 0 of the menstrual cycle. Menstrual cycle phases were determined via selfreports of menstruation and cycle length. All anthropometric and RMR measurements were taken at least three times per week for the duration of one complete menstrual cycle in all subjects. In addition, measurements were taken for a second, consecutive menstrual cycle in eight of the nineteen subjects. As the length of the menstrual cycle varied between subjects, each menstrual cyle was normalized and expressed as a percentage of 100. The first day of the menstrual cycle was marked as $0 \%, 100 \%$ represented the day before the beginning of the next menses and ovulation roughly corresponded to $50 \%$ of the cycle. This allowed comparisons to be made between subjects. Technical error of measurement and coefficient of reliability $(R)$ were determined using formulae given by Ulijaszek \& Kerr (1999). Measurement error values for body weight and RMR were $0.4 \mathrm{~kg}$ and $197 \mathrm{~kJ}$ respectively and 1.0 and 0.91 respectively $(R)$.

\section{Statistical analysis}

Statistical analysis was performed using the Statistical Package for Social Sciences (SPSS 10.0.5, 1999; SPSS Inc., Chicago, IL, USA). Results are presented as mean values and standard deviations. Before statistical analysis, the normality of the data was tested using the ShapiroWilks statistic. When data were not normally distributed (BMI; body weight and lean body mass in the second menstrual cycle), a logarithmic transformation was applied to satisfy assumptions of normality; data were transformed back for presentation in tables and figures. Levels of inter- and intra-individual variation of body weight and RMR were assessed by determining the CV (\%). Paired $t$ tests were used to determine differences in mean body weight and RMR between menstrual cycles 1 and 2 . Statistical significance was set at $P<0 \cdot 05$.

RMR data were transformed to $\log$ scale to remove the dependence of the variation on mean value (Fig. 1). Random-effects models (Pinheiro \& Bates, 2000) with different random effects and different models of betweenand within-subject variation were fitted to the data with the statistical package $\mathrm{R}$ (The $\mathrm{R}$ Project for Statistical Computing, 2002) using the nlme package. Each model 


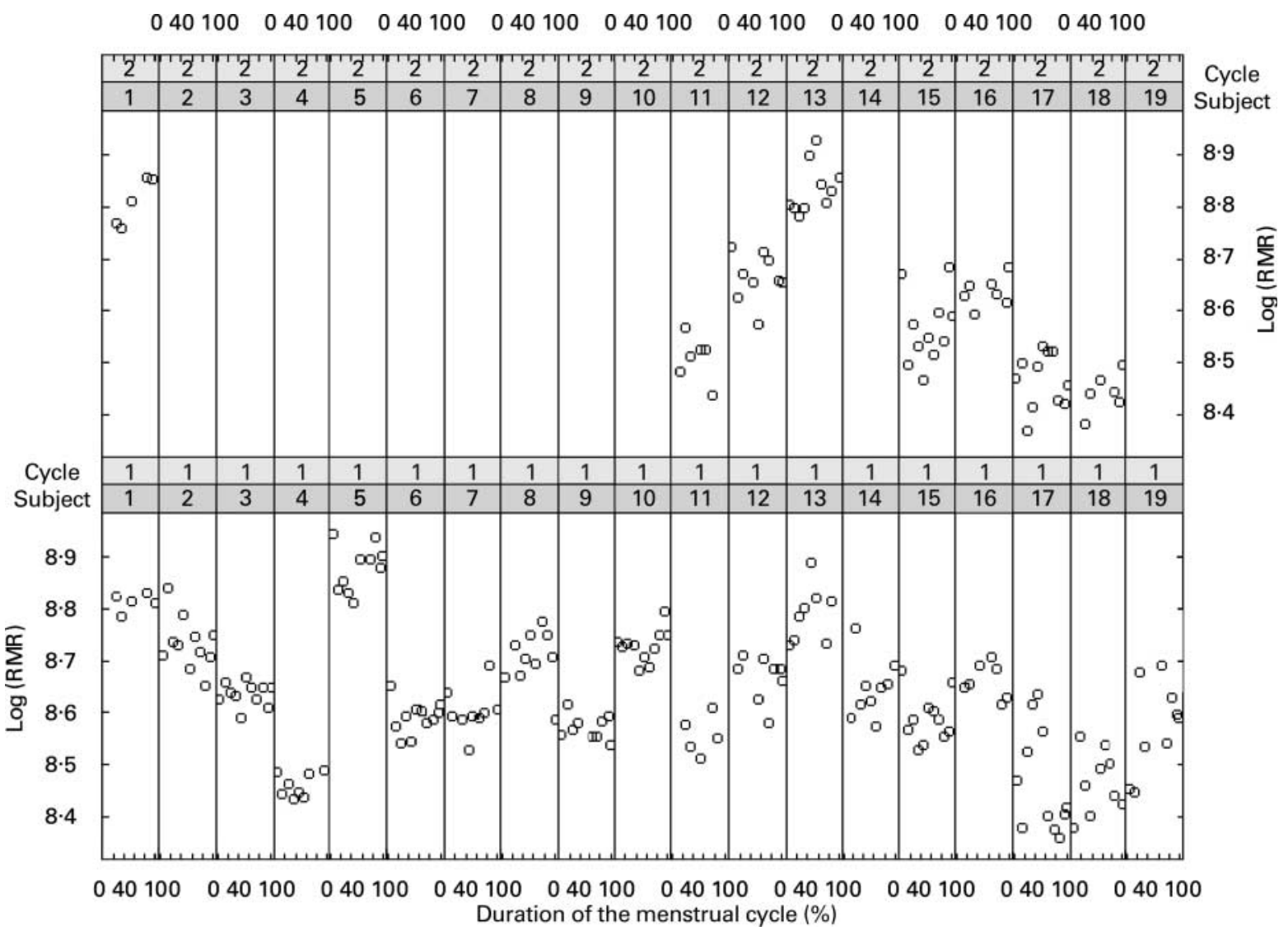

Fig. 1. Plot of log (resting metabolic rate (RMR)) through time. Each menstrual cycle is expressed as a percentage of 100 . For details of subjects and procedures, see Table 1 and p. 812 .

was fitted using the method of restricted maximum likelihood (ReML). The models were compared using likelihood ratio tests to determine the significant model components. The models fitted were: model 1 (a random effect for subject); model 2 (model $1+$ a random effect for session); model 3 (model $1+$ an exponential model of temporal correlation within each menstrual cycle); model 4 (model $3+$ subject-specific variance parameters); model 5 (model $4+\mathrm{a}$ term specifying exponential decay of the variance through time); and model 6 (model $3+$ a term specifying exponential decay of the variance through time). Comparing models 1 and 2, the session random effect did not significantly improve the model fit $(P=0.8611)$ and so this component was omitted from subsequent models.

\section{Results}

Mean menstrual cycle length was 30 (SD 4) (range 24-41) d. There were no significant differences in body weight for any subject during the duration of the study. Intra-individual variation in body weight ranged from 0.3 to $1.9 \%$ (Table 2).

Mean RMR was 5686 (SD 674) kJ (1359 (SD 325) kcal)/d. Expressed per unit body weight, mean RMR was 84 (SD 12) $\mathrm{kJ} / \mathrm{kg}$ per d. Inter-individual CV for RMR was $11.8 \%$. Fig. 2 shows the variation in RMR for all subjects. Mean intraindividual variation in RMR expressed as $\mathrm{CV}$ was 4.6 (SD 2.2) (range 1.7-10.4) \%. The intra-individual variations in RMR and RMR expressed per unit body weight were similar $(P=0.646$; Table 3$)$. There was a high level of intra-individual variation in RMR during the menstrual cycle. The CV in ten subjects was at a level similar

Table 2. Intra-individual variation in body weight* (Mean values, standard deviations and ranges)

\begin{tabular}{|c|c|c|c|c|}
\hline \multirow[b]{2}{*}{ Subject } & \multicolumn{4}{|c|}{ Body weight (kg) } \\
\hline & Mean & SD & Range & CV $(\%)$ \\
\hline 1 & $104 \cdot 2$ & 0.3 & $104 \cdot 0-104 \cdot 5$ & 0.3 \\
\hline 2 & $79 \cdot 7$ & 0.3 & $79 \cdot 3-80 \cdot 4$ & 0.4 \\
\hline 3 & $69 \cdot 2$ & 0.3 & $68 \cdot 4-69 \cdot 7$ & 0.5 \\
\hline 4 & $52 \cdot 0$ & 0.3 & $51 \cdot 6-52 \cdot 4$ & 0.6 \\
\hline 5 & $90 \cdot 1$ & 0.6 & $89 \cdot 0-90 \cdot 5$ & 0.6 \\
\hline 6 & 53.5 & 0.4 & $53 \cdot 0-54 \cdot 2$ & 0.7 \\
\hline 7 & 51.5 & 0.4 & $51 \cdot 0-52 \cdot 0$ & 0.7 \\
\hline 8 & $73 \cdot 1$ & 0.5 & $72 \cdot 2-74 \cdot 0$ & 0.7 \\
\hline 9 & $72 \cdot 2$ & 0.6 & $71 \cdot 3-73 \cdot 1$ & 0.8 \\
\hline 10 & $88 \cdot 7$ & 0.7 & $87 \cdot 6-89 \cdot 7$ & 0.8 \\
\hline 11 & $56 \cdot 3$ & 0.4 & $56 \cdot 0-57 \cdot 0$ & 0.8 \\
\hline 12 & 67.9 & 0.5 & $67 \cdot 2-68 \cdot 5$ & 0.8 \\
\hline 13 & $92 \cdot 7$ & 0.7 & $91 \cdot 8-94.0$ & 0.8 \\
\hline 14 & $64 \cdot 1$ & 0.5 & $63 \cdot 5-65 \cdot 0$ & 0.8 \\
\hline 15 & $56 \cdot 9$ & 0.6 & $56 \cdot 0-58 \cdot 0$ & $1 \cdot 0$ \\
\hline 16 & $55 \cdot 3$ & 0.6 & $54.5-56 \cdot 3$ & $1 \cdot 2$ \\
\hline 17 & 51.5 & 0.7 & $50 \cdot 5-52.5$ & $1 \cdot 3$ \\
\hline 18 & $66 \cdot 9$ & 1.3 & $65 \cdot 5-68 \cdot 5$ & 1.9 \\
\hline 19 & $67 \cdot 8$ & $1 \cdot 3$ & $66 \cdot 0-69 \cdot 5$ & 1.9 \\
\hline
\end{tabular}

${ }^{*}$ For details of subjects, see Table 1. 


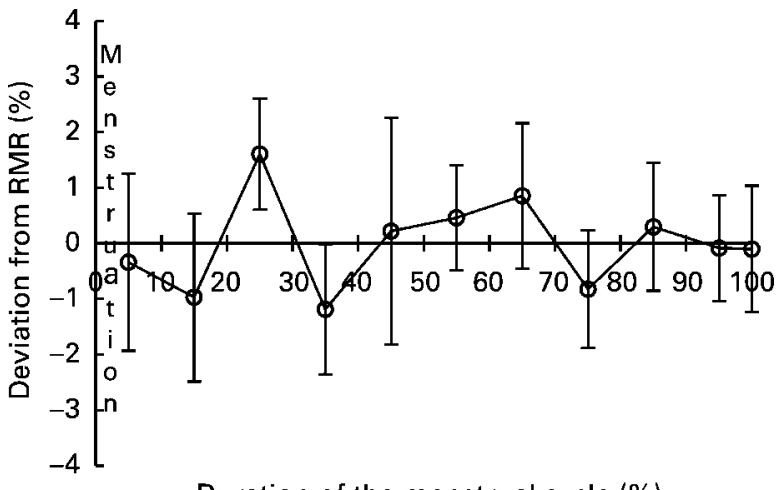

Duration of the menstrual cycle (\%)

Fig. 2. Variation in resting metabolic rate (RMR) during the menstrual cycle. Each menstrual cycle is expressed as a percentage of 100 and the average variation at intervals of $10 \%$ determined. Ovulation roughly corresponds to $50 \%$. For details of subjects and procedures, see Table 1 and p. 812. Values are the average deviation from the mean for nineteen subjects with their standard errors represented by vertical bars.

to that observed in men (2-4\%) (Henry et al. 1989). The remaining subjects $(n 9)$ had a much greater variation in their RMR (CV 5-10\%). This indicates that there may be a significant variation in RMR during the menstrual cycle in some subjects.

Variation in RMR of representative subjects (two with a low $\mathrm{CV}(<4 \%)$ and two with a high $\mathrm{CV}(>5 \%))$ is illustrated in Fig. 3. This figure illustrates the point that there is considerable biological variation in RMR during the menstrual cycle.

To assess whether there was a subject-specific component of variance, random-effects models were fitted to the data. The addition of a temporal correlation within each menstrual cycle (model 2 compared with model 3) significantly improved the model fit $(P=0 \cdot 0025)$. Fig. 4 shows the subject residuals from the model 3 fit and indicates that there may be a subject-specific level of variation. Comparing models 3 and 4, the addition of a subjectspecific variance significantly improved the model fit $(P=0 \cdot 0001)$. Comparing models 4 and 5, the addition of a term allowing a decay in variation through time did not significantly improve the fit $(P=0 \cdot 1505)$. Finally, the subject-specific variance parameters were still significant in the presence of a possible decrease in variation through time (model 5 compared with model 6). This analysis suggests that within-cycle temporal correlation and subject-specific variation were significant factors in models for the data.

Data were collected during two consecutive menstrual cycles in eight subjects. Mean body weight was similar in cycles 1 and 2: 69.0 (SD 19.3) and 68.4 (SD 19.9) kg respectively $(P=0 \cdot 228)$. Mean RMR was 5622 (SD 742) $\mathrm{kJ} / \mathrm{d}$ and 85 (SD 14) $\mathrm{kJ} / \mathrm{kg}$ per $\mathrm{d}$ in cycle 1 and 5576 (SD $851) \mathrm{kJ} / \mathrm{d}$ and 84 (SD 14) $\mathrm{kJ} / \mathrm{kg}$ per d in cycle $2(P=0.451$ and $P=0.908$ respectively). Fig. 5 shows the variation in RMR during the menstrual cycles.

There was little difference in intra-individual variation in body weight and RMR between the two menstrual cycles (Table 4). At the group level, mean intra-individual CV in body weight was 1.0 (SD 0.5) $\%$ in cycle 1 and 0.9 (SD 0.2$) \%$ in cycle $2(P=0.410)$. Mean intra-individual $\mathrm{CV}$ in RMR was 5.0 (SD 2.6) and 4.6 (SD 1.2) \% in cycles 1 and 2 respectively $(P=0 \cdot 680)$.

The pattern of RMR during each menstrual cycle of two representative subjects is shown in Fig. 6. This figure illustrates the point that there was no significant difference in the pattern of RMR between the two cycles.

Table 3. Intra-individual variation in resting metabolic rate $(\mathrm{RMR})^{*}$ (Mean values, standard deviations and ranges)

\begin{tabular}{|c|c|c|c|c|c|c|c|c|}
\hline \multirow[b]{2}{*}{ Subject† } & \multicolumn{4}{|c|}{ RMR (kJ/d) } & \multicolumn{4}{|c|}{ RMR (kJ/kg per d) } \\
\hline & Mean & SD & Range & CV (\%) & Mean & SD & Range & CV $(\%)$ \\
\hline 1 & 6718 & 116 & $6530-6830$ & 1.7 & 64 & 1 & $63-66$ & 1.7 \\
\hline 3 & 5627 & 127 & $5377-5810$ & $2 \cdot 3$ & 81 & 2 & $77-83$ & $2 \cdot 4$ \\
\hline 4 & 4720 & 107 & $4592-4853$ & $2 \cdot 3$ & 91 & 2 & $89-93$ & 1.9 \\
\hline 9 & 5279 & 127 & $5097-5511$ & $2 \cdot 4$ & 73 & 2 & $70-76$ & $2 \cdot 4$ \\
\hline 10 & 6182 & 194 & $5889-6600$ & $3 \cdot 1$ & 70 & 2 & $67-74$ & $2 \cdot 8$ \\
\hline 6 & 5381 & 170 & $5127-5723$ & $3 \cdot 2$ & 101 & 3 & $95-108$ & 3.4 \\
\hline 16 & 5776 & 193 & $5523-6046$ & $3 \cdot 3$ & 105 & 3 & $101-109$ & $3 \cdot 1$ \\
\hline 11 & 5202 & 195 & $4977-5479$ & 3.7 & 92 & 4 & $87-98$ & 4.4 \\
\hline 12 & 5807 & 246 & $5319-6054$ & 4.2 & 86 & 3 & $79-88$ & 3.7 \\
\hline 7 & 5450 & 240 & $5050-5940$ & 4.4 & 106 & 5 & $97-116$ & 4.8 \\
\hline 5 & 7185 & 323 & $6709-7670$ & 4.5 & 80 & 4 & $75-85$ & 4.4 \\
\hline 15 & 5374 & 261 & $5050-5895$ & 4.9 & 95 & 5 & $87-105$ & 5.4 \\
\hline 2 & 6210 & 322 & $5708-6914$ & $5 \cdot 2$ & 78 & 4 & $71-87$ & 5.4 \\
\hline 8 & 6030 & 318 & $5363-6475$ & $5 \cdot 3$ & 82 & 5 & $72-88$ & 5.5 \\
\hline 13 & 6567 & 362 & $6186-7243$ & $5 \cdot 5$ & 71 & 4 & $66-78$ & $5 \cdot 6$ \\
\hline 14 & 5687 & 331 & $5280-6389$ & $5 \cdot 8$ & 89 & 5 & $83-98$ & $5 \cdot 4$ \\
\hline 18 & 4752 & 290 & $4350-5188$ & $6 \cdot 1$ & 71 & 4 & $66-78$ & $5 \cdot 4$ \\
\hline 19 & 5303 & 463 & $4650-5949$ & $8 \cdot 7$ & 79 & 8 & $70-92$ & $9 \cdot 8$ \\
\hline 17 & 4781 & 496 & $4272-5630$ & $10 \cdot 4$ & 93 & 10 & $82-109$ & 10.5 \\
\hline
\end{tabular}

${ }^{*}$ For details of subjects and procedures, see Tables 1 and 2 and p. 812 † Subjects listed in ascending order of CV. 
(a)
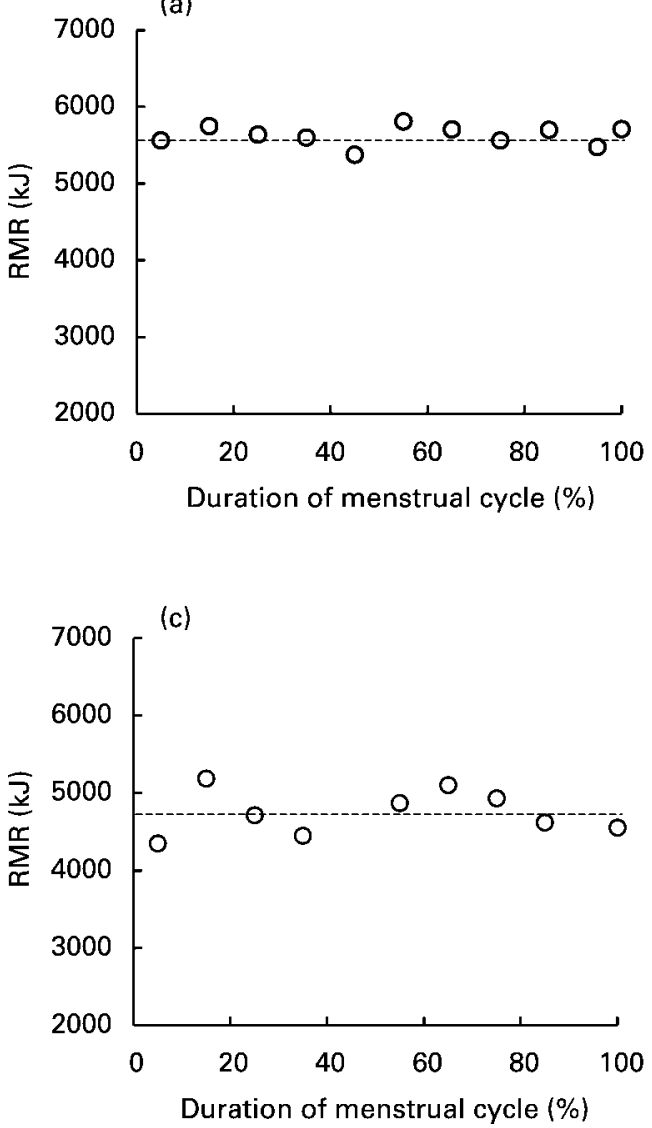

(b)

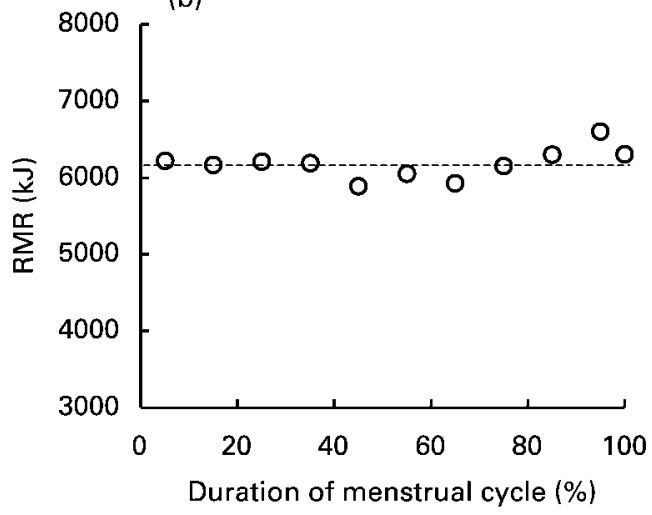

(d)

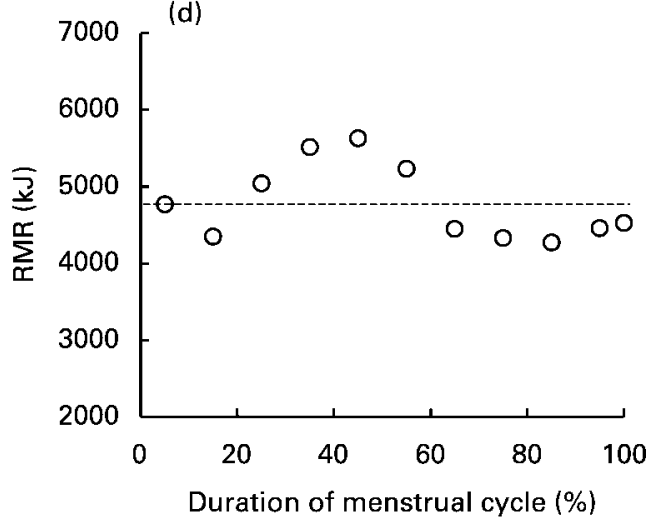

Fig. 3. Resting metabolic rate (RMR) of representative subjects with a low or high CV (\%). (a) Subject 3; (b) subject 10; (c) subject 18; (d) subject 17. - - -, Mean RMR. Each menstrual cycle is expressed as a percentage of 100. The first day of the menstrual cycle is marked as $0 \%$ and $100 \%$ represents the day before the beginning of the next menstrual period; ovulation roughly corresponds to $50 \%$ of the menstrual cycle. For details of subjects and procedures, see Tables $2-3$ and p. 812.

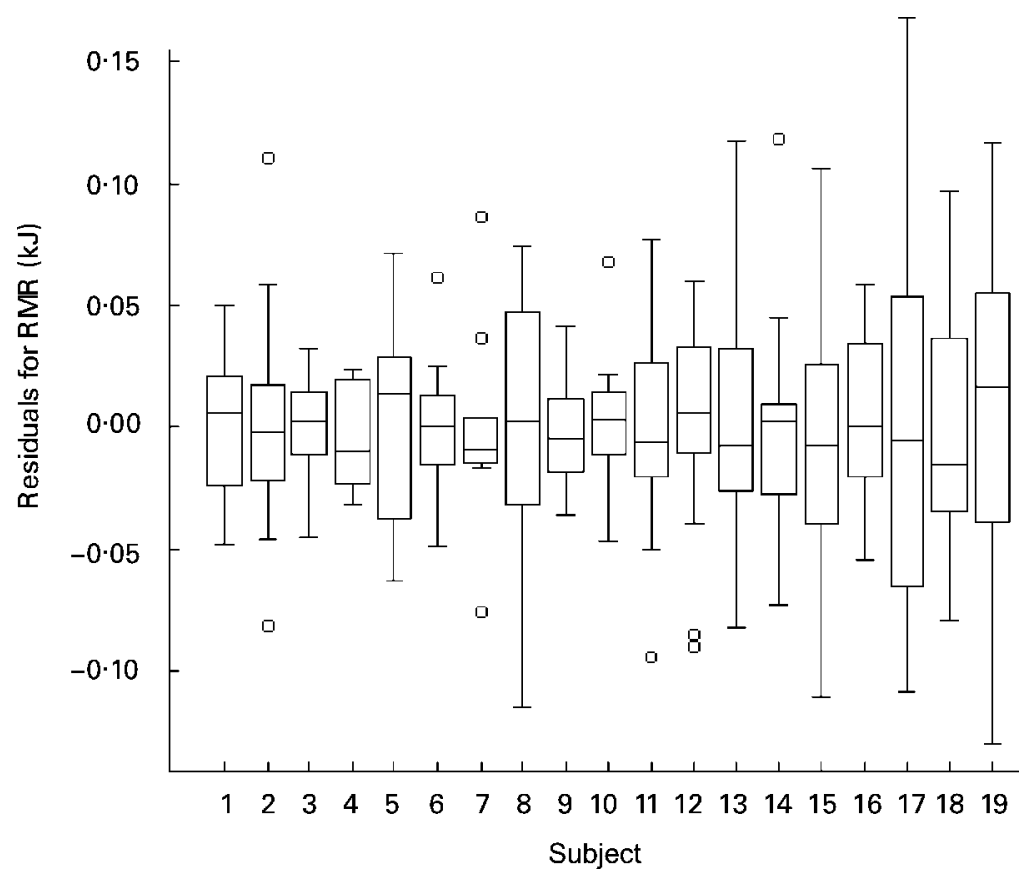

Fig. 4. Box plots graph representing statistical residuals of resting metabolic rate (RMR) for each subject from the model 3 fit. For details of the model and procedures, see p. 812. Vertical bars above and below the box indicate the 90th and 10th percentiles; (O), outlying values. 


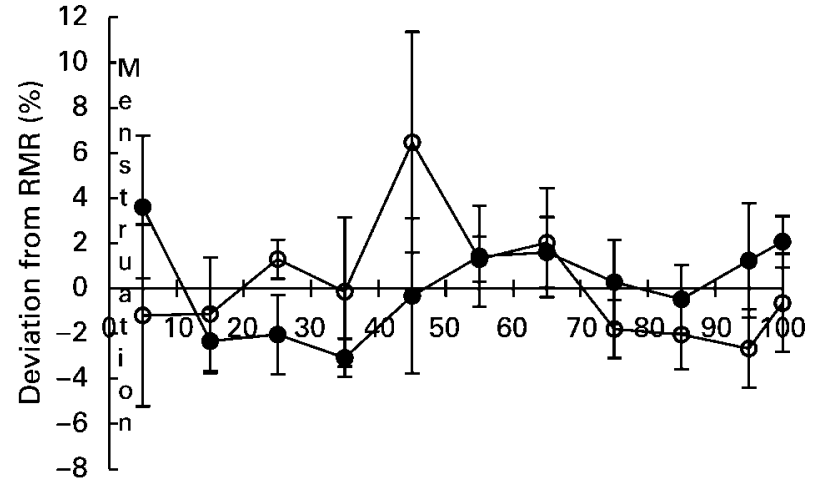

Duration of the menstrual cycle (\%)

Fig. 5. Variation in resting metabolic rate (RMR) during menstrual cycles $1(\mathrm{O})$ and $2(\bullet)$. Each menstrual cycle is expressed as a percentage of 100 and the average variation at intervals of $10 \%$ determined. Ovulation corresponds roughly to $50 \%$. For details of subjects and procedures, see p. 812. Each value represents the average deviation from the mean for eight subjects with their standard errors represented by vertical bars.

Table 4. Intra-individual variation (\%) in body weight and RMR for menstrual cycles 1 and 2 in eight subjects* (Coefficients of variation)

\begin{tabular}{lccccc}
\hline & \multicolumn{2}{c}{ Body weight } & & \multicolumn{2}{c}{ RMR } \\
\cline { 2 - 3 } \cline { 5 - 6 } Subject & Cycle 1 & Cycle 2 & & Cycle 1 & Cycle 2 \\
\hline 1 & 0.3 & 0.5 & & 1.7 & 4.5 \\
11 & 0.8 & 0.8 & & 3.7 & 4.3 \\
12 & 0.8 & 1.1 & & 4.2 & 4.1 \\
13 & 0.8 & 0.7 & & 5.5 & 4.9 \\
15 & 1.0 & 1.2 & & 4.9 & 6.9 \\
16 & 1.2 & 1.0 & & 3.3 & 2.9 \\
17 & 1.3 & 0.9 & & 10.4 & 5.3 \\
18 & 1.9 & 0.7 & & 6.1 & 3.9
\end{tabular}

* For details of subjects and procedures, see Tables 1 and 2 and p. 812

\section{Discussion}

The present study was an attempt to quantify the inter- and intra-individual variation in RMR during the menstrual cycle in naturally cycling women, and in particular to assess whether there was a subject-specific component of variance. This present study is of importance as RMR underpins the calculation of energy requirements of both individuals and populations; thus, a better understanding of the variability in RMR is essential in predicting energy requirements.

The biphasic pattern of RMR during the menstrual cycle (a fall in RMR with the onset of menstruation and a peak before the next menstrual period) observed in previous studies (Solomon et al. 1982; Curtis et al. 1996a) was not evident in our present study. However, considerable dayto-day variability of RMR was observed in some women. Some subjects did exhibit minor peaks in RMR during the late luteal phase or slight troughs in RMR during the early follicular phase, although differences in RMR during the follicular and luteal phases of the menstrual cycle were considered too small to be of any significance. Moreover, as ovulation was predicted from cycle length and not assessed biochemically, accurate determination of the luteal phase of the menstrual cycle could not be made.

Previous studies have suggested that the inter-individual variation in RMR in both men and women is at least $8 \%$ (Henry et al. 1989; Soares et al. 1989; Spurr et al. 1994). The findings from our present study substantiate this. In addition, our present study demonstrated that there are wide differences in the intra-individual variation in RMR in women and that this was the case even when accounting for a possible training effect. This is similar to findings from previous research (Solomon et al. 1982; Spurr et al. 1994; Curtis et al. 1996a).

In our present study, intra-individual variation in RMR in certain women was similar to that observed in men (Henry et al. 1989). However, intra-individual variation in RMR in nine subjects studied was greater, indicating (a)

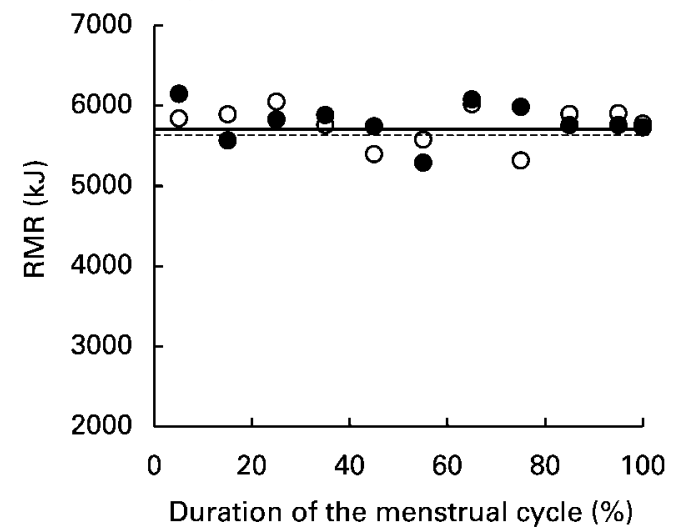

(b)

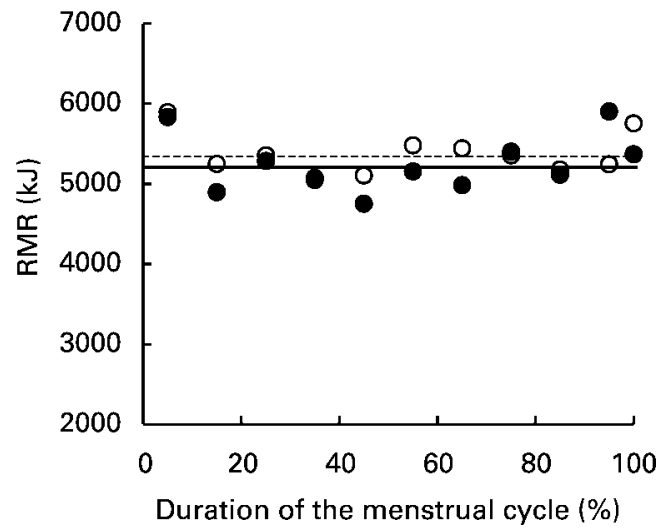

Fig. 6. Resting metabolic rate (RMR) of subjects (a) 15 and (b) 17 during menstrual cycles $1(\mathrm{O}$; - --, mean RMR) and $2(\bullet$; -, mean RMR). Each menstrual cycle is expressed as a percentage of 100 . The first day of the menstrual cycle is marked as $0 \%$ and $100 \%$ represents the day before the beginning of the next menstrual period; ovulation roughly corresponds to $50 \%$ of the menstrual cycle. For details of subjects and procedures, see p. 812 . 
that there may be a significant variation in the menstrual cycle variation of each subject. For simplicity, two 'metabolic' type of women may be identified: those with low (CV 2-4\%) and those with high (CV 5-10\%) intraindividual variation in RMR.

It has been suggested that some of the intra-individual variation in RMR may be attributed to training effect or familiarization with the procedure involved in the measurement of RMR (Soares \& Shetty, 1986). However, using the statistical models outlined previously, the findings from the present study indicate that there was a significant effect on RMR due to a subject-specific level of variability and this was evident even when the training effect was taken into account.

There are limited results available on between-cycle differences in RMR. Of the studies that have collected RMR data for 2 months or more, results have either been averaged (Solomon et al. 1982) or agreement between cycles has been analysed in one particular phase of the menstrual cycle only (Piers et al. 1995). Findings from the present study show little difference in intra-individual variation in RMR between the two menstrual cycles and this was observed at the group level.

Subjects in this current study were all naturally cycling non-pill users. It has been suggested that RMR in pillusers is not as variable as the RMR in normally ovulating women (Curtis et al. 1996b). This change in the variability of RMR may influence energy balance. Thus, due to the extensive use of oral contraceptive pills worldwide, their impact on RMR (and hence energy balance) needs to be investigated.

In conclusion, the findings from our present study show that RMR cannot be assumed to be 'stable' in all women. The implications of intra-individual variation in RMR during the menstrual cycle and its impact on energy balance and body weight regulation needs further research. A better understanding of the variation in RMR during the menstrual cycle may provide insights into the ability of certain women to maintain energy balance more effectively.

\section{Acknowledgements}

This study was supported in part by The Sugar Bureau. We thank Donna Wilson for her assistance in part of the data collection.

\section{References}

Blunt K \& Dye M (1921) Basal metabolism of normal women. Journal of Biological Chemistry 47, 69-87.

Bray GA (1997) Historical framework for the development of ideas about obesity. In Handbook of Obesity, pp. 1-30 [GA Bray, C Bouchard and WPT James, editors]. New York: Marcel Dekker.

Curtis V, Henry CJK, Birch E \& Ghusain-Choueiri A (1996a) Intraindividual variation in the basal metabolic rate of women: effect of the menstrual cycle. American Journal of Human Biology 8, 631-639.

Curtis V, Henry CJK \& Ghusain-Choueiri A (1996b) Basal metabolic rate of women on the contraceptive pill. European Journal of Clinical Nutrition 50, 319-322.

Durnin JVGA \& Womersley J (1974) Body fat assessed from total body density and its estimation from skinfold thickness: measurements on 481 men and women aged from 16 to 72 years. British Journal of Nutrition 32, 77-97.

Erens B \& Primatesta P (1999) Health Survey for England: Cardiovascular Disease 98. London: The Stationery Office.

Food and Agriculture Organization/World Health Organization/ United Nations University (1985) Energy and Protein Requirements. Report of a Joint FAO/WHO/UNU Expert Consultation. Technical Report Series no. 724. Geneva: WHO.

Gibson RS (1991) Principles of Nutritional Assessment. New York: Oxford University Press.

Henry CJK, Hayter J \& Rees DG (1989) The constancy of basal metabolic rate in free-living male subjects. European Journal of Clinical Nutrition 43, 727-731.

Hitchcock FA \& Wardwell FR (1929) Cyclic variations in the basal metabolic rate of women. Journal of Nutrition 2, 203-215.

Howe JC, Rumpler WV \& Seale JL (1993) Energy expenditure by indirect calorimetry in premenopausal women - variation within one menstrual cycle. Journal of Nutritional Biochemistry 4, 268-273.

James WPT \& Ralph A (1999) New understanding in obesity research. Proceedings of the Nutrition Society 58, 385-393.

Meijer GAL, Westerterp KR, Saris WHM \& Tenhoor F (1992) Sleeping metabolic rate in relation to body composition and the menstrual cycle. American Journal of Clinical Nutrition 55, 637-640.

Piers LS, Diggavi SN, Rijskamp J, Vanraaij JMA, Shetty PS \& Hautvast J (1995) Resting metabolic rate and thermal effect of a meal in the follicular and luteal phases of the menstrual cycle in well nourished Indian women. American Journal of Clinical Nutrition 61, 296-302.

Pinheiro JC \& Bates DM (2000) Mixed-Effects Models in S and $S$-PLUS. New York: Springer-Verlag.

Shetty PS \& Soares MJ (1988) Variability in basal metabolic rates of man. In Comparative Nutrition, pp. 141-148 [K Blaxter and I Macdonald, editors]. London: John Libbey.

Soares MJ, Piers LS, Kraai L \& Shetty PS (1989) Day-to-day variations in basal metabolic rates and energy intakes of human subjects. European Journal of Clinical Nutrition 43, $465-472$.

Soares MJ \& Shetty PS (1986) Intra-individual variations in resting metabolic rates of human subjects. Human Nutrition: Clinical Nutrition 40C, 365-369.

Solomon SJ, Kurzer MS \& Calloway DH (1982) Menstrual cycle and basal metabolic rate in women. American Journal of Clinical Nutrition 36, 611-616.

Spurr GB, Dufour DL, Reina JC, Hoffmann RG, Waslien CI \& Staten LK (1994) Variation of the basal metabolic rate and dietary energy intake of Colombian women during $1 \mathrm{y}$. American Journal of Clinical Nutrition 59, 20-27.

The R Project for Statistical Computing (2002) http://www. r-project.org.

Ulijaszek SJ \& Kerr DA (1999) Anthropometric measurement error and the assessment of nutritional status. British Journal of Nutrition 82, 165-177.

Wakeham G (1923) Basal metabolism and the menstrual cycle. Journal of Biological Chemistry 56, 555-567.

Weststrate JA (1993) Resting metabolic rate and diet-induced thermogenesis: a methodological reappraisal. American Journal of Clinical Nutrition 58, 592-601.

Wiltshire MOP (1921) Some observations on basal metabolism in menstruation. Lancet 2, 388-389. 